九州大学学術情報リポジトリ

Kyushu University Institutional Repository

\title{
Effect of Grain Price Support Policy in China : A Grey Relational Analysis
}

Qian, Jiarong

Laboratory of Food and Agricultural Policy, Division of Agricultural Policy, Department of Agricultural and Resource Economics, Graduate School of Bioresource and Bioenvironmental

Sciences, Kyushu University

Ito, Shoichi

Faculty of Agriculture, Kyushu University

Mu, Yueying

College of Economics and Management, China Agricultural University

Isoda, Hiroshi

Faculty of Agriculture, Kyushu University

https://doi.org/10.5109/27382

出版情報: 九州大学大学院農学研究院紀要. 58 (2)，pp.485-491，2013-09. Faculty of Agriculture， Kyushu University

バージョン :

権利関係 : 


\title{
Effect of Grain Price Support Policy in China: A Grey Relational Analysis
}

\author{
Jiarong QIAN ${ }^{*}$, Shoichi ITO ${ }^{2}$, Yueying MU $^{3}$ and Hiroshi ISODA ${ }^{2}$
}

\author{
Laboratory of Food and Agricultural Policy, Division of Agricultural Policy, Department of Agricultural and \\ Resource Economics, Faculty of Agriculture, Kyushu University, \\ Fukuoka 812-8581, Japan \\ (Received April 26, 2013 and accepted May 9, 2013)
}

\begin{abstract}
Since 2004 the minimum purchasing price policy has been implemented in China and the policy effect attracts extensive attention. This paper introduces this current grain price support policy and assesses the effect of this policy on regulating China domestic grain prices employing the grey relational analysis. The results suggest that price support policy plays a most important role in determining grain market prices relative to other factors including production cost, international price and production, implying that the policy impacts the grain market prices effectively and the expected goals of this policy have been achieved. Therefore, in controlling grain market prices, employing grain minimum purchasing price policy is efficient, and continuing efforts should be made to design appropriate minimum purchasing prices for grains.
\end{abstract}

Key words: grey relational analysis, policy effect, price support

\section{INTRODUCTION}

Since 2003, food production in China has been steadily increasing. Grain production increased from 374 million tons in 2003 to 496 million tons in 2010, growing by $32.6 \%$. Facing the increasing production, grain prices are forced to decline. In order to avoid decreasing prices which will hurt grain supply, in 2004 the Chinese government started to employ grain minimum purchasing price policy (MPPP) to maintain the stability of grain market prices, which aims to stabilize grain production and protect the income of farmers.

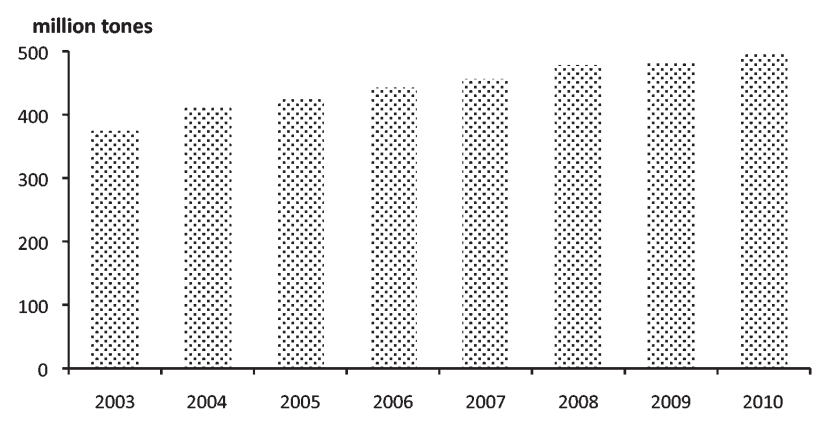

Fig. 1. Total grain production in China from 2003 to 2010 Source: China Agricultural Development Report 2011.

The effect of this policy receives much attention from academics and policy makers, and the studies on this topic are many. Qu (2006) explained grain minimum purchasing price policy in details, and pointed out

\footnotetext{
${ }^{1}$ Laboratory of Food and Agricultural Policy, Division of Agricultural Policy, Department of Agricultural and Resource Economics, Graduate School of Bioresource and Bioenvironmental Sciences, Kyushu University

Faculty of Agriculture, Kyushu University

3 College of Economics and Management, China Agricultural University

* Corresponding author (E-mail: golden1008@126.com)
}

the differences between the protective price policy and minimum purchasing price policy. Yang (2006), Wang (2006), Huang (2006) and Yun (2010) concluded that the MPPP enhances farmers' income and stabilizes grain market prices effectively based on studying annual income and price data. Liu (2009) analyzed the policy effects from economic theory. He concluded that in theory the MPPP is helpful to protect farmer's interests and to keep grain prices and production stable. Wang (2010) found that food price policy is a major factor influencing food market prices, and he summarized the influences of different price support policies on food market prices in different periods. Li (2011) pointed out that against the background of agricultural product prices declining $6.2 \%$ in the first half year of 2009, the prices of rice and wheat increased by $4.9 \%$ and $8.7 \%$, respectively, after the implementation of MPPP for rice and wheat. However most studies are based on theoretical or descriptive analyses and up until now, no empirical study on evaluating the effect of MPPP is found due to a short policy implementing period. In order to fill this gap in the literature, we attempt to employ grey relational analysis method which only requires a very limited data sample to empirically examine how significant this policy factor is among the determinants of grain market prices, and seek to provide more convincing information for policy making.

\section{EVOLUTION OF GRAIN PRICE SUPPORT POLICY IN CHINA}

Supporting grain prices not only can protect the farmers from price fluctuations but also encourages growth in the grain supply. Therefore price support policy is often regarded as an ideal policy tool for government intervention in the grain market. Since 2004, the Chinese government has been employing MPPP in main grain producing areas to regulate grain market prices. This policy is to set a minimum purchasing price each 
year for each grain in the implemented areas and if the grain market prices are below the minimum purchasing price, the grain enterprises delegated by the government will start to purchase grains from market at the minimum purchasing prices until the grain prices are above the minimum price. In 2004, rice became the first crop covered by this policy. In the policy, rice is divided into two categories, the early season rice including early season long grain rice and the mid-late season rice including middle season long grain rice, late season long grain rice and medium grain rice. For rice, the implementing areas were expanded in 2008. The implemented areas of early season rice were expanded from 4 provinces to 5 provinces, all of which are located in southern China, the early season rice share in national production rose from $59 \%$ to $75 \%$; the implemented areas of Mid-late season rice increased from 7 provinces with a production of 91.2 million tons in 2009 to 11 provinces producing 124.7 million tons of mid-late season rice in 2009, the mid-late season rice share in national production rose from $57 \%$ to $78 \%$. For wheat, the minimum purchasing price policy was enforced in 5 main producing provinces and the number of provinces covered has stayed unchanged since the implementation year of 2006. Those provinces are Hebei, Jiangsu, Anhui, Shandong, Henan, and Hubei, in which the total wheat production was 88.5 million tons in 2009, accounting for $77 \%$ of the total wheat production in China (See Table 1).

Due to the different harvest times, the policy implementing periods are different for grains. Basically, the implemented period for rice is from sep.16 to Dec.31, but because Jilin, Heilongjiang and Liaoning are located in northern China, the harvest season for rice often comes later, the implemented period in these areas is from the last year's Nov.16 to the next year's Mar.31. For wheat the implementing period is from each year's May.21 to Sep.30. The announced time of a policy is also important as it may influence the effect of a policy. For early season rice, the minimum purchasing prices are often announced in each July, about two months before the implemented time. For middle and late season rice, the announced time is in September of each year, only a few days before the implemented time in the southern producing areas, but two months before the implemented period in the northern areas. In the case of wheat, the minimum purchasing prices are often announced in each May, also several days before the period of implementation (See Table 2).

Table 3 reports the annual minimum purchasing prices for each grain. Rice minimum purchasing price policy provides three minimum price levels for four types of rice (early season long grain rice, middle season long grain rice, late season long grain rice, and medium grain rice). The minimum prices for early season long grain rice are relatively lower than the other three types of rice. In 2004 it was set at 70 yuan $/ 50 \mathrm{~kg}$, and increased to 102 yuan $/ 50 \mathrm{~kg}$ in 2011, up 45.7\%. Middle and late long grain rice always share the same minimum price each year; the minimum prices for these two grains increased from 72 yuan $/ 50 \mathrm{~kg}$ in 2004 to 107 yuan $/ 50 \mathrm{~kg}$ in 2011, an increase of $48.6 \%$. In medium grain rice's case, its minimum prices are higher than other rice. The minimum price was set at a level of 75 yuan $/ 50 \mathrm{~kg}$

Table 1. Changes in main producing areas covered by MPPP (million tons)

\begin{tabular}{cllcc}
\hline Grain & \multicolumn{1}{c}{ Period } & \multicolumn{1}{c}{ Province covered } & Production & Share (\%) \\
\hline $\begin{array}{c}\text { Early } \\
\text { season rice }\end{array}$ & $2004-2007$ & Anhui, Jiangxi, Hubei, Hunan & 19.62 & 59 \\
\hline \multirow{2}{*}{$\begin{array}{c}\text { Mid-late } \\
\text { season rice }\end{array}$} & $2008-$ & Anhui, Jiangxi, Hubei, Hunan, Guangxi & 25.16 & 75 \\
\hline 2004-2007 & Jilin, Heilongjiang, Anhui, Jiangxi, Hubei, Hunan, Sichuan & $\begin{array}{l}\text { Jilin, Heilongjiang, Anhui, Jiangxi, Hubei, Hunan, Sichuan, Liaoning, } \\
\text { Jiangsu, Henan, Guangxi }\end{array}$ & 124.71 & 57 \\
\hline Wheat & $2006-$ & Hebei, Jiangsu, Anhui, Shandong, Henan, Hubei & 88.46 & 78 \\
\hline
\end{tabular}

Source: China Agricultural Yearbook 2010. Note: the production was the total production of the covered provinces in 2009; the percent indicates the production share of the covered areas in the national production.

Table 2. The implemented periods and announced time of MPPP for main producers

\begin{tabular}{clcc}
\hline Grain & \multicolumn{1}{c}{ Province covered } & Implemented period & Announced time \\
\hline $\begin{array}{c}\text { Early } \\
\text { harvested } \\
\text { rice }\end{array}$ & Anhui, Jiangxi, Hubei, Hunan, Guangxi & Sep.16-Dec.31 & July \\
\hline $\begin{array}{c}\text { Mid-late } \\
\text { harvested rice }\end{array}$ & Sichuan, Jiangsu, Henan, Guangxi, Anhui, Jiangxi, Hubei, Hunan & Sep.16-Dec.31 & September \\
\hline Wheat & Hebei, Jiangsu, Anhui, Shandong, Henan, Hubei & Nov.16-Mar.31 & September \\
\hline
\end{tabular}

Note: The implemented period for Liaoning and Heilongjiang before 2008 was from previous Nov. 10 to Feb. 28. The implemented period for wheat before 2008 was from Jun. 1 to Sep. 30 . 
in 2004, and in 2011 it went up to 128 yuan $/ 50 \mathrm{~kg}$, increasing by $70.6 \%$, which was the biggest increase among the different rice varieties.

Wheat has been divided into three categories (white wheat, red wheat, and mixed wheat) in the wheat minimum purchasing price policy system according to the properties of the wheat. The minimum price for white wheat is higher than that of red wheat and mixed wheat. It was set at 72 yuan $/ 50 \mathrm{~kg}$ in 2006 and increased to 95 yuan $/ 50 \mathrm{~kg}$ in 2011, up 31.9\%. Red wheat and mixed wheat share the same rate of minimum price, their minimum prices were 69 yuan $/ 50 \mathrm{~kg}$ in 2006, and increased to 93 yuan $/ 50 \mathrm{~kg}$ in 2011, increased by $34.8 \%$. Generally, after 2008 grain minimum prices started to increase annually. This indicates that the Chinese government is making a major effort to tilt policy support towards agricultural development.

\section{GRAIN MINIMUM PURCHASING PRICES AND MARKET PRICES}

Table 4 reports changes in minimum purchasing prices, grain prices and the difference between these two prices. The smaller difference indicates the more similar movements the two prices have. The annual minimum purchasing prices are averaged to represent the overall level of rice prices. In the implementation year of 2004, under the support of minimum prices, all grain market prices saw big jumps. The early season rice price increased 24.5 yuan $/ 50 \mathrm{~kg}$ from 51.6 yuan $/ 50 \mathrm{~kg}$ in 2003 to 76.1 yuan $/ 50 \mathrm{~kg}$ in 2004 , and the increases in prices of middle season rice, late season rice and medium grain rice were 19.9 yuan $/ 50 \mathrm{~kg}, 18.2$ yuan $/ 50 \mathrm{~kg}$ and 17.3 yuan $/ 50 \mathrm{~kg}$, respectively. The average price of all rice increased from 60.1 yuan $/ 50 \mathrm{~kg}$ to 79.8 yuan $/ 50 \mathrm{~kg}$, an increase of 19.7 yuan $/ 50 \mathrm{~kg}$. Note that in the case of medium grain rice, the differences are quite stable from 2004 to 2009, the market prices always stay an average of 12 yuan $/ 50 \mathrm{~kg}$ higher than the minimum purchasing prices, reflecting very similar movements between the two prices of medium grain rice. Generally, market prices moved above the minimum purchasing prices and the differences between these two prices are small, exhibiting similarities in the annual movements between minimum prices and market prices.

According to the evolution of this price support policy, we divide the implementation into three periods: 2003-2004 (for wheat is 2005-2006), which is the starting period of implementation; 2004-2007 (for wheat is 2006-2007), in which the minimum prices remained

Table 3. Changes in grain minimum purchasing prices (yuan/50 kg)

\begin{tabular}{|c|c|c|c|c|c|c|c|}
\hline \multirow{2}{*}{ Year } & \multicolumn{4}{|c|}{ Rice } & \multicolumn{3}{|c|}{ Wheat } \\
\hline & Ear-LG & Mid-LG & Late- LG & MG & White & Red & Mixed \\
\hline 2004 & 70 & 72 & 72 & 75 & - & - & - \\
\hline 2005 & 70 & 72 & 72 & 75 & - & - & - \\
\hline 2006 & 70 & 72 & 72 & 75 & 72 & 69 & 69 \\
\hline 2007 & 70 & 72 & 72 & 75 & 72 & 69 & 69 \\
\hline 2008 & 77 & 79 & 79 & 82 & 77 & 72 & 72 \\
\hline 2009 & 90 & 92 & 92 & 95 & 87 & 83 & 83 \\
\hline 2010 & 93 & 97 & 97 & 105 & 90 & 86 & 86 \\
\hline 2011 & 102 & 107 & 107 & 128 & 95 & 93 & 93 \\
\hline
\end{tabular}

Source: Annual governmental documents.

Table 4. Grain market prices and minimum prices in China (yuan/50 kg)

\begin{tabular}{|c|c|c|c|c|c|c|c|c|c|}
\hline \multirow{2}{*}{ Year } & \multicolumn{3}{|l|}{ Ear- } & \multicolumn{3}{|l|}{ Mid } & \multicolumn{3}{|l|}{ Late } \\
\hline & Price & MP & $\Delta \mathrm{P}$ & Price & $\mathrm{MP}$ & $\Delta \mathrm{P}$ & Price & $\mathrm{MP}$ & $\Delta \mathrm{P}$ \\
\hline 2003 & 51.6 & - & - & 55.5 & - & - & 63.7 & - & - \\
\hline 2004 & 76.1 & 70.0 & 6.1 & 75.4 & 72.0 & 3.4 & 81.9 & 72.0 & 9.9 \\
\hline 2005 & 72.7 & 70.0 & 2.7 & 71.3 & 72.0 & -0.7 & 76.9 & 72.0 & 4.9 \\
\hline 2006 & 75.2 & 70.0 & 5.2 & 73.9 & 72.0 & 1.9 & 81.6 & 72.0 & 9.6 \\
\hline 2007 & 80.9 & 70.0 & 10.9 & 82.5 & 72.0 & 10.5 & 90.3 & 72.0 & 18.3 \\
\hline 2008 & 96.6 & 77.0 & 19.6 & 92.5 & 79.0 & 13.5 & 99.1 & 79.0 & 20.1 \\
\hline 2009 & 96.0 & 90.0 & 6.0 & 94.4 & 92.0 & 2.4 & 99.2 & 92.0 & 7.2 \\
\hline 2010 & 102.4 & 93.0 & 9.4 & 109.2 & 97.0 & 12.2 & 120.0 & 97.0 & 23.0 \\
\hline
\end{tabular}

Source: Cost and Return of Agricultural Commodities Yearbook in China 2011. Note: MP indicates minimum purchasing price, $\Delta \mathrm{P}$ is the difference between grain price and minimum purchasing price. 
Table 4. Continued

\begin{tabular}{|c|c|c|c|c|c|c|c|c|c|}
\hline \multirow{2}{*}{ Year } & \multicolumn{3}{|c|}{ MG } & \multicolumn{3}{|c|}{ Rice } & \multicolumn{3}{|c|}{ Wheat } \\
\hline & Price & MP & $\Delta \mathrm{P}$ & Price & $\mathrm{MP}$ & $\Delta \mathrm{P}$ & Price & $\mathrm{MP}$ & $\Delta \mathrm{P}$ \\
\hline 2003 & 68.2 & - & - & 60.1 & - & - & 56.4 & - & - \\
\hline 2004 & 85.5 & 75.0 & 10.5 & 79.8 & 73.2 & 6.7 & 74.5 & - & - \\
\hline 2005 & 88.4 & 75.0 & 13.4 & 77.7 & 73.2 & 4.5 & 69.0 & - & - \\
\hline 2006 & 89.8 & 75.0 & 14.8 & 80.6 & 73.2 & 7.5 & 71.6 & 70.0 & 1.6 \\
\hline 2007 & 87.1 & 75.0 & 12.1 & 85.2 & 73.2 & 12.0 & 75.6 & 70.0 & 5.6 \\
\hline 2008 & 93.4 & 82.0 & 11.4 & 95.1 & 80.2 & 14.9 & 82.8 & 73.7 & 9.1 \\
\hline 2009 & 105.8 & 95.0 & 10.8 & 99.1 & 93.2 & 5.9 & 92.4 & 84.3 & 8.1 \\
\hline 2010 & 136.9 & 105.0 & 31.9 & 118.0 & 100.3 & 17.7 & 99.0 & 87.3 & 11.7 \\
\hline
\end{tabular}

Source: Cost and Return of Agricultural Commodities Yearbook in China 2011. Note: MP indicates minimum purchasing price, $\Delta \mathrm{P}$ is the difference between grain price and minimum purchasing price.

Table 5. Increase rates of minimum prices and market prices for each grain (\%)

\begin{tabular}{clllllll}
\hline Period & Price type & ELG & MLG & LLG & MG & Rice & Wheat \\
\hline \multirow{2}{*}{$2003-2004$} & Market price & 47.6 & 35.9 & 28.7 & 25.3 & 32.9 & 32.0 \\
& Minimum price & - & - & - & - & - & - \\
\multirow{2}{*}{$2004-2007$} & Market price & 6.3 & 9.5 & 10.2 & 1.9 & 6.8 & 5.5 \\
& Minimum price & 32.9 & 34.7 & 34.7 & 40.0 & 37.1 & 24.8 \\
\multirow{2}{*}{$2007-2010$} & Market price & 26.6 & 32.3 & 32.9 & 57.2 & 38.5 & 31.0 \\
\hline
\end{tabular}

Source: Authors' calculation. Note: ELG, early season long grain rice; MLG, middle season long grain rice; LLG, late season long grain rice; $\mathrm{MG}$, medium grain rice. Rice indicates the average level of rice.

unchanged; 2007-2010, which is the period that grain minimum prices started to increase annually. Table 5 reports changes in increase rate of minimum purchasing prices and market prices for each grain in different periods. In the first period, we witness a big jump in all grain market prices in 2004, the price of early long grain rice went up $47.6 \%$, which was the biggest increase, other rice prices rose by $35.9 \%, 28.7 \%$ and $25.3 \%$, respectively, and the average rice price increased by $32.9 \%$. Note that wheat price also increased in 2004 due to the high correlation with rice price, it increased by $32.0 \%$. These big increases in grain market prices reflect that the price support policy has an obvious impact on grain market prices in the starting year of the policy implementation. In the second period, where the minimum prices stayed unchanged, grain prices had experienced small increases without increasing supports from policies. Most of the grains increased by less than 10\% from 2004 to 2007, but the price of medium grain rice only increased by $1.9 \%$ in this period compared to big jumps in the first period. In the third period, when the Chinese government raised the minimum purchasing prices drastically, with the minimum prices rising, dramatic increases in grain market prices followed. The average minimum price of rice increased by $37.1 \%$, the average rice price increased by $38.5 \%$, and for wheat the two prices had increased by $24.8 \%$ and $31.0 \%$, respectively.

Comparing the increases in the three periods, we find that grain market prices increased dramatically when the price support policy was implemented in 2004; when the minimum prices remained unchanged, grain market prices were more stable; as minimum prices started to increase, grain market prices also witnessed big increases. The movements of the minimum prices and the market prices remain highly simultaneous, indicating MPPP shows significant influences on grain market prices.

The descriptive analysis shows that the policy may effectively affect the grain market prices, but how significant the influence of this price support policy is and if this policy is a main factor determining the movements of grain market prices will be examined in the next part of this paper by employing a grey relational analysis.

\section{METHODOLOGY AND DATA}

The grey relational analysis is a branch of grey system theory developed by Dr. Deng $(1982,1989)$, which is often applied to search for primary relationships among the factors and to determine the significant factors influencing a specific objective. Since its emergence, the grey relational analysis method has been widely applied in many fields. For example, it has been applied in the finance field (Kung and Yu, 2008; Wu, Lin, and Tasi, 2010; Zhang, 2012), in the industry field (Hsu and Wang, 2009), in the energy field (Lin, Lu and Lewis, 2007; Lu, Lin and Lewis, 2008), in the agricul- 
tural field (Yun, 2010; Zhao, Mu and Ito, 2012), and so on. As different from the regression analysis, grey relational analysis only requires small size data sets, and also does not require data subject to a normal distribution. In grey relational analysis, a concept of grey relational grade is known as the measure of relevancy between two factors, describing the trend relationship between an objective sequence and a reference sequence in a system from the point of view of geometrical mathematics. The more both trends tend towards concordance, the larger the grey relational grade is, or otherwise the smaller. Grey relational analysis first calls for the normalization of raw data to remove anomalies so that the data in different units can be comparable to each other. Two types of normalizing processing, initial-value processing and average-value processing, are often used to transform the raw data into dimensionless form. The former divides the elements in each sequence by the first component, which is generally applied to data series without an apparent increasing or decreasing trend. The latter uses the average value of the sequence as the divisor, which is more appropriate for the data series with increasing or decreasing trend. Via dealing with the finite raw data using grey processing, the regularity between objective sequence and reference sequence can be found out using the grey relational analysis method.

Assuming there is an objective sequence $Y_{0}=\left\{y_{0}(1)\right.$, $\left.y_{0}(2), \ldots, y_{0}(n)\right\}$, and a reference sequence $Y_{i}=\left\{y_{i}(1)\right.$, $\left.y_{i}(2), \ldots, y_{i}(n)\right\}$, the normalized data are $X_{0}=\left\{x_{0}(1)\right.$, $\left.x_{0}(2), \ldots, x_{0}(n)\right\}$ and $X_{i}=\left\{x_{i}(1), x_{i}(2), \ldots, x_{i}(n)\right\}, i=1,2, \ldots, m$, $n$ denoting the sample size of objective sequence and reference sequences, $m$ being the number of reference sequences. The grey relational coefficient between $x_{0}(k)$ and $x_{i}(k)$ can then be defined as

$$
r_{0 i}(k)=\frac{\min _{i} \min _{k}\left|x_{0}(k)-x_{i}(k)\right|+\theta \max _{i} \max _{k}\left|x_{0}(k)-x_{i}(k)\right|}{\left|x_{0}(k)-x_{i}(k)\right|+\theta \boldsymbol{\operatorname { m a x }} \max \left|x_{0}(k)-x_{i}(k)\right|}
$$

where $k=1,2, \ldots, n, \theta$ is the distinguishing coefficient in the range between 0 and 1 , and often with a value of 0.5 . The grey relational grade between the objective sequence and the reference sequence is known as

$$
r_{0 i}=\frac{1}{n} \sum \rho_{0 i}(k)
$$

It numerically measures the influence degree of factors to the objective variable, and the numerical values are bounded by 0 and 1 . Generally, $r>0.9$ indicates a marked influence, $r>0.8$ a relatively marked influence, $r>0.7 \mathrm{a}$ noticeable influence, $\mathrm{r}<0.6$ a negligible influence $(\mathrm{Fu}$ and Zheng, 2001). Assessing the effect of a policy is based on the basic assumption that the higher the grey relational grade, the more effective the policy is.

The policy aims to affect grain market prices, thus the annual grain prices are selected as the objective sequence $\left(X_{0}\right)$ and the minimum purchasing prices are selected as a reference sequence $\left(X_{1}\right)$. In order to determine how significant the minimum purchasing price is among the factors influencing grain market prices, we introduce three other main drivers, grain production cost $\left(X_{2}\right)$, international grain price $\left(X_{3}\right)$ and grain production $\left(X_{4}\right)$, as objects for making comparisons with the policy factor. Grain price data are collected from China Agricultural Development Report 2011; the minimum purchasing price data $\left(X_{1}\right)$ are collected from annual government document; the international price data come from China Agricultural Development Report 2011. Production cost data are from Cost and Return of Agricultural Commodities Yearbook in China 2011. The study periods are from 2004 to 2010 for rice and from 2006 to 2010 for wheat. Price data and cost data are all deflated by China's consumer price index with a base year of 2004. The original data for rice and wheat are shown in Table 6 and the mean value of each sequence is also reported in the table so as to normalize the raw data.

\begin{tabular}{|c|c|c|c|c|c|c|c|c|}
\hline Variable & 2004 & 2005 & 2006 & 2007 & 2008 & 2009 & 2010 & Mean \\
\hline & \multicolumn{8}{|c|}{ rice } \\
\hline$X_{0}$ & 79.82 & 76.29 & 78.04 & 78.69 & 82.94 & 87.01 & 100.31 & 83.30 \\
\hline$X_{1}$ & 73.17 & 71.87 & 70.81 & 67.57 & 69.91 & 81.82 & 85.30 & 74.35 \\
\hline$X_{2}$ & 49.06 & 54.85 & 56.12 & 55.70 & 61.24 & 63.61 & 71.44 & 58.86 \\
\hline$X_{3}$ & 245.78 & 282.72 & 293.75 & 306.96 & 610.59 & 517.58 & 442.54 & 376.23 \\
\hline \multirow[t]{2}{*}{$X_{4}$} & 125.36 & 126.41 & 127.20 & 130.22 & 134.33 & 136.57 & 139.30 & 131.34 \\
\hline & \multicolumn{8}{|c|}{ wheat } \\
\hline$X_{0}$ & - & - & 69.30 & 69.80 & 72.17 & 81.15 & 84.17 & 73.11 \\
\hline$X_{1}$ & - & - & 67.75 & 64.64 & 64.24 & 74.06 & 74.24 & 67.67 \\
\hline$X_{2}$ & - & - & 53.69 & 54.29 & 54.27 & 64.13 & 69.35 & 59.15 \\
\hline$X_{3}$ & - & - & 185.55 & 235.67 & 284.23 & 196.21 & 190.15 & 225.41 \\
\hline$X_{4}$ & - & - & 108.47 & 109.30 & 112.46 & 115.12 & 114.50 & 111.97 \\
\hline
\end{tabular}

Table 6. Raw data of rice and wheat

Source: Authors' calculation. 
Table 7. Average-value processing for raw data

\begin{tabular}{|c|c|c|c|c|c|c|c|}
\hline Variable & 2004 & 2005 & 2006 & 2007 & 2008 & 2009 & 2010 \\
\hline & \multicolumn{7}{|c|}{ rice } \\
\hline$X_{0}$ & 0.96 & 0.92 & 0.94 & 0.94 & 1.00 & 1.04 & 1.20 \\
\hline$X_{1}$ & 0.98 & 0.97 & 0.95 & 0.91 & 0.94 & 1.10 & 1.15 \\
\hline$X_{2}$ & 0.83 & 0.93 & 0.95 & 0.95 & 1.04 & 1.08 & 1.21 \\
\hline$X_{3}$ & 0.90 & 1.05 & 0.93 & 0.76 & 1.10 & 1.27 & 1.19 \\
\hline \multirow[t]{2}{*}{$X_{4}$} & 0.92 & 0.94 & 0.95 & 1.00 & 1.06 & 1.05 & 1.08 \\
\hline & \multicolumn{7}{|c|}{ wheat } \\
\hline$X_{0}$ & - & - & 0.95 & 0.95 & 0.99 & 1.11 & 1.15 \\
\hline$X_{1}$ & - & - & 1.00 & 0.96 & 0.95 & 1.09 & 1.10 \\
\hline$X_{2}$ & - & - & 0.91 & 0.92 & 0.92 & 1.08 & 1.17 \\
\hline$X_{3}$ & - & - & 1.07 & 1.06 & 1.00 & 0.88 & 0.73 \\
\hline$X_{4}$ & - & - & 0.93 & 0.97 & 1.03 & 1.02 & 1.05 \\
\hline
\end{tabular}

Source: Authors' calculation.

Table 8. Grey relational grades between crop price and its influencing factors

\begin{tabular}{|c|c|c|c|c|c|c|}
\hline Factors & ELG & MLG & LLG & MG & Rice & Wheat \\
\hline $\operatorname{Minimum}$ price $\left(X_{1}\right)$ & 0.883 & 0.852 & 0.850 & 0.895 & 0.881 & 0.841 \\
\hline Production $\operatorname{cost}\left(X_{2}\right)$ & 0.850 & 0.855 & 0.872 & 0.875 & 0.854 & 0.807 \\
\hline International price $\left(X_{3}\right)$ & 0.620 & 0.621 & 0.623 & 0.610 & 0.618 & 0.455 \\
\hline $\operatorname{Production}\left(X_{4}\right)$ & 0.557 & 0.562 & 0.560 & 0.552 & 0.553 & 0.774 \\
\hline
\end{tabular}

Source: Authors' calculation. Note: ELG, early season long grain rice; MLG, middle season long grain rice; LLG, late season long grain rice; MG, medium grain rice. Rice indicates the average level of rice.

\section{EMPIRICAL RESULTS}

As a first step for grey relational analysis, we must transform the raw data into dimensionless forms by average-value processing due to the increasing trend nature of the data. Table 7 reports the processed data of rice average and wheat.

We calculate the grey relational grades with the processed data. The results are listed in Table 8. For the average level of rice, the relational grade of rice minimum purchasing price to rice price is 0.881 which is the largest value among the selected factors, indicating a noticeable influence of MPPP on rice prices and the influence from the policy factor is the most significant compared with other factors; then followed by rice production cost and international rice price, and rice production, the grey relational grades are $0.854,0.618$ and 0.553 for rice production cost, international rice price and rice production, respectively. For the four types of rice, the relational grades of minimum purchasing prices are also large, particularly, for medium grain rice, it reached 0.895 , which is the largest among grains, indicating strong influences of MPPP on rice market prices. In the case of wheat, the grades of minimum purchasing price, production cost, international price and wheat production are $0.841,0.807,0.455$ and 0.774 , respectively. The minimum price relational grade is also the largest coinciding with rice cases.

Generally, among the main determinants, the MPPP has the largest grey relational grade, showing it has the most important influence on grain market prices and determining the movements of grain prices; production costs is the second most important factor affecting grain prices; while the impulse from international grain prices to China domestic grain prices seems to be small, and only with a grey relational grade of approximately 0.6 for rice and less than 0.5 for wheat, reflecting that the international grain prices have negligible influences on China domestic grain prices. This is because of the government intervenes extensively in the grain markets, resulting in domestic prices diverging from world market prices. Grain production is also not significantly related to changes in grain market prices. Actually, in recent years they exhibit the same rather than reverse movements with grain prices due to a series of agricultural support policies. The main conclusion of this research is that the MPPP effectively impacts grain prices and has the most significant influence on grain market prices relative to other factors selected.

\section{CONCLUSIONS}

This paper introduced the implementation of current grain price support policy in China and measured how 
significant the policy factor is among the factors influencing grain prices employing the grey relational analysis to calculate the grey relational grades between grain prices and their determinants. The results suggest that the minimum purchasing price policy is a major factor determining grain market prices, and among the determinants of grain market prices selected, the price support policy plays a most significant role, providing convincing evidence that the grain minimum purchasing price policy impacts grain market prices effectively and therefore the expected goals of this policy have been achieved. We conclude that for regulation of grain market prices, the current price support policy is a most efficient tool in aiming to protect farmers from price variability and increase farmers' income and agricultural supply, continuing efforts should be made to design appropriate minimum purchasing prices for grains.

\section{REFERENCES}

Deng, J. L. 1982 Control problems of grey system theory. Syst. Control. Lett., 1(5): 288-294

Deng, J. L. 1989 Introduction to grey system theory. J. Grey. Syst-UK., 1(1): 1-24

Fu, C. Y. and Zheng, J. S. 2001 Application of grey relational analysis for corrosion failure of oil tubes. Corros. Sci., 43(5): 881889

Huang, Y. Z. 2006 Economic analysis on grain minimum purchasing price policy in China. Finance and Economy, 6: 13-15

Hsu, L. C. and Wang, C. H. 2009 Forecasting integrated circuit output using multivariate grey model and grey relational analysis. Expert. Syst. Appl., 36(2): 1403-1409

Kung, L. M. and Yu, S. W. 2008 Prediction of index futures returns and the analysis of financial spillovers: A comparison between GARCH and the grey theorem. Eur. J. Oper. Res., 186(3): 1184-1200

Li, G. X. 2011 Economic analysis on increasing agricultural product prices in China. Expanding Horizons, 1: 19-21

Li, W. W. 2011 Applying grey relational analysis to evaluate the factors affecting innovation capability. Canadian Social Science, 7(3): 119-124

Lin, S. J., Lu, I. J. and Lewis, C. 2007 Grey relation performance correlations among economics, energy use and carbon dioxide emission in Taiwan. Energ. Policy., 35(3): 1948-1955

Liu, R. 2009 Effect of food minimum purchasing price policy. Grain Science and Technology and Economy, 1: 13-14

Lu, I. J., Lin, S. J. and Lewis, C. 2008 Grey relation analysis of motor vehicular energy consumption in Taiwan. Energ. Policy., 36(7): 2556-2561

Qu, S. 2006 Rice minimum purchasing price policy. Grain Issues Research., 1: 33-36

Wang, C. 2010 The factors influencing food market prices in China Agricultural Economy, 7: 24-27

Wang, W. J. 2006 Improving grain minimum purchasing price policy and Chinese food security. Prices Monthly, 10: 1-6

Wu, C. R., Lin, C. T. and Tasi, P. H. 2010 Evaluating business performance of wealth management banks. Eur. J. Oper. Res. 207(2): 971-979

Yang, G. Y. 2006 Analysis on the effect of grain minimum purchasing price policy. Price: theory\& practice, 6: $35-36$

Yun, W. 2010 Gray relevance analysis of investments and growth of agriculture. Contemporary Economy \& Management, 32(10): 2010

Zhang, X. 2012 Venture capital investment base on grey relational theory. Physics Procedia, 33: 1825-1832

Zhao, X., Mu, Y. and Ito, S. 2012 Comparative analysis on influence factors of urban vegetable production in China: based on data of Beijing, Shanghai and Hangzhou. J. Fac. Agr. Kyushu. U., 57(1): 353-363 